\title{
El activismo jurisprudencial de la Corte Interamericana de Derechos Humanos
}

\author{
Judicial activism of the Interamerican Court of Human Rights
}

Ruth Martinón Quintero

Universidad de La Laguna, España

\begin{abstract}
RESUMEN En el contexto del debate actual acerca de la proliferación de tribunales internacionales y sus consecuencias, este artículo estudia los factores que en teoría deberían promover su activismo jurisprudencial. En concreto, se observa su incidencia en la labor de la Corte Interamericana de Derechos Humanos, al tiempo que se traen a colación las principales críticas a su activismo. Así, se pone de manifiesto que, en este caso concreto, la base de las divergencias entre las opiniones opuestas surge de concepciones distintas del derecho internacional y su relación con los derechos internos de los Estados, y, más concretamente, con la defensa o no de la existencia de un derecho internacional global de los derechos humanos.
\end{abstract}

PALABRAS CLAVE Tribunales internacionales, activismo judicial internacional, Corte Interamericana de Derechos Humanos, derecho internacional de los derechos humanos.

ABSTRACT Within the current debate about the proliferation of international tribunals and its consequences, this article studies the factors that in theory should promote the jurisprudential activism of such tribunals. In particular, we see their impact on the work of the Inter-American Court of Human Rights, while the main criticisms of its activism are raised. Thereby, it is exposed that at least in this specific case the basis of the divergences between the opposing opinions arise from different conceptions of international law and its relation to the domestic laws, and, more specifically, to the defense or not of the existence of a global international law of human rights.

KEYWORDS International courts, international judicial activism, Interamerican Court of Human Rights, International Law on Human Rights. 


\section{Introducción}

El derecho vive en un constante diálogo con la realidad social. Surgen nuevas normas para regular nuevos hechos o relaciones con relevancia jurídica, pero también para intentar cambiar la realidad. El impulso de los procesos que llevan a esos cambios del ordenamiento jurídico puede proceder de muy diversas fuentes, y en el camino hasta la consolidación del nuevo derecho pueden participar muchas instancias distintas. En ocasiones, los tribunales de justicia juegan un papel destacado en este proceso al desarrollar su labor con activismo creativo en pro de objetivos, valores y principios considerados superiores del ordenamiento jurídico, si bien con frecuencia rozan con su actuación el límite de su propia legitimidad. Algunos tribunales internacionales juegan en repetidas ocasiones ese papel.

En este caso nos centramos en el estudio del papel de la Corte Interamericana de Derechos Humanos como tribunal internacional activo en su compromiso con hacer realidad la vigencia de los derechos humanos en los Estados bajo su jurisdicción por el interés que despierta su actividad en sí misma, pero también por el debate doctrinal que ha suscitado.

Para ello, en primer lugar, presentaremos brevemente del papel de la jurisprudencia en el derecho internacional y el concepto de activismo jurisprudencial como elemento básico del contexto institucional del debate sobre el papel jugado por la Corte IDH. Estos aspectos son fundamentales porque las críticas al tribunal interamericano se reconducen a la denuncia de su activismo y mayormente se plantean desde una determinada concepción del derecho internacional en general, y del derecho internacional de los derechos humanos en particular.

En segundo lugar, analizaremos la labor de la Corte IDH haciendo uso del marco analítico propuesto por Zarbiyev (2012), quien sistematiza los aspectos más proclives a facilitar un mayor margen de actuación de los tribunales internacionales de justicia. De modo que no se trata de un estudio de la jurisprudencia de la Corte para colegir su mayor o menor creatividad o activismo, sino que, atendiendo al marco propuesto por este autor, observamos otros aspectos que a su parecer también sirven para analizar la existencia o la probabilidad de ese activismo. Si bien defendemos el carácter fuertemente subjetivo de la etiquetación de una decisión judicial como activismo, consideramos que este instrumento teórico permite identificar características que favorecen la presencia de ese comportamiento por parte de los tribunales de justicia en general y de los tribunales internacionales en particular. Es esa capacidad para sistematizar los factores que pueden ser determinantes del modo de actuar de los tribunales al proveer elementos de valor más allá de las opiniones, lo que consideramos que dota de un especial valor a esta propuesta teórica.

En el recorrido por el análisis de esos factores, nos detendremos en las críticas y los elogios que ha despertado la labor de la Corte para de este modo alcanzar una mejor comprensión de su trabajo y de su aportación a la jurisprudencia internacional en materia de derechos humanos, al tiempo que nos permite situar en perspectiva los co- 
mentarios en uno y otro sentido que ha despertado su labor. Por esta razón, la elección de las sentencias y opiniones consultivas que sirven para argumentar cada uno de los apartados se ha hecho en función de la mayor controversia que han despertado desde la perspectiva del activismo judicial y por su vínculo con el hilo argumental de cada uno de los factores estudiados.

\section{La jurisprudencia en el derecho internacional: Artículo 38 ETIJ frente a la realidad}

El artículo 38.1.d) del Estatuto de la Corte Internacional de Justicia (ETIJ), marco de referencia del sistema de fuentes del derecho internacional, recoge las decisiones judiciales solo como un medio auxiliar para la determinación de las reglas de derecho. Sin embargo, la importancia de la jurisprudencia internacional es evidente y no ha dejado de crecer (Von Bogdandy y Venzke, 2012: 19). Su relevancia tiene origen en las propias características del ordenamiento jurídico internacional, en el que los jueces no solo han tenido que interpretar la norma, sino también con mucha frecuencia han de constatar y precisar la existencia de normas consuetudinarias o de los mismos principios generales y los principios estructurales del derecho internacional. ${ }^{1}$

Otra razón que explica la importancia de la jurisprudencia internacional es la proliferación de órganos jurisdiccionales (Abalde Cantero, 2016: 77-78) principalmente desde los años noventa y vinculada al fin de la Guerra Fría, el ensanchamiento de las materias reguladas por el derecho internacional y la aparición de nuevos actores internacionales configurados como sujetos de derecho internacional: principalmente, las organizaciones internacionales (con frecuencia con sus propios tribunales), pero también los particulares ambicionando algunas de sus características. Ello les abre las puertas a que se les reconozca la posibilidad de acceder a los tribunales internacionales, antes exclusivamente abiertos a los Estados.

Este proceso de judicialización del ordenamiento internacional lleva a preguntarse si se trata solo de un fenómeno cuantitativo o si, por el contrario, supone también una profundización de la función jurisdiccional en el derecho internacional. Es decir, cabe preguntarse si la proliferación de estos mecanismos judiciales de solución de controversias ha conllevado una modificación del perfil general del derecho internacional como ordenamiento pobre de jurisdicción, debido al papel fundamental que juega en el mismo el principio de libertad en la elección del medio de arreglo de controversias y, por tanto, la libertad de los Estados para someterse o no a los procesos jurisdiccionales, como expresión de su soberanía. Si eso fuese así, podría afirmarse que esa judicialización de las relaciones internacionales se correspondería con un proceso de maduración del sistema jurídico internacional, un «cambio de

1. Aunque también destaca su papel en el impulso de la transformación del soft law en hard law, la expansión de la relación entre costumbre y tratado, o dotando de autoridad al proceso de codificación de la Comisión de Derecho Internacional (Boyle y Chinkin, 2007: 269). 
paradigma producido en el interior del sistema de solución de controversias» (Bellei Tagle, 2016: 18). Este autor considera que se trata de un fenómeno que contribuye al proceso de institucionalización y legitimación del derecho internacional en su conjunto, al tiempo que se hace eco de los peligros que se han vislumbrado ligados a esta proliferación: el riesgo de fragmentación del derecho internacional sustantivo y el posible desencadenamiento de conflictos de jurisdicción. ${ }^{2}$ Abalde, por su parte, resalta cómo el mayor protagonismo adquirido por los tribunales en la esfera internacional ha supuesto la necesidad de evaluar su credibilidad, legitimidad y eficacia, ligada a la utilización por parte de estos tribunales «de criterios cada vez más cercanos a los estándares propios de sistemas nacionales, lo que a nuestro juicio, debe ser entendido como un signo de madurez del propio sistema judicial internacional» (Abalde Cantero, 2016: 421).

Dentro de esta reflexión general es que consideramos interesante encuadrar el estudio del activismo judicial en el ámbito internacional. El incremento del número de órganos jurisdiccionales en el ordenamiento internacional y la relevancia de su actividad ha generado un debate acerca de ellos. Se hace necesario reflexionar sobre hasta qué punto la labor de los tribunales internacionales está yendo más allá de la aplicación e interpretación de la norma para constituirse en verdaderos creadores de derecho. ${ }^{3}$ Es necesario observar la labor de la Corte IDH y sus críticos dentro de esta perspectiva más amplia que abarca lo que está sucediendo en el mundo de hoy con los tribunales internacionales y el derecho internacional.

\section{¿Qué entendemos por activismo judicial?}

La noción de activismo judicial ${ }^{4}$ parte siempre, aunque mayoritariamente implícita, de la concepción de la división de poderes y del Estado de derecho en la que el poder judicial se concibe como un poder sometido al ordenamiento jurídico que ha de limitarse a resolver los litigios atendiendo a lo dispuesto en tal ordenamiento. ${ }^{5}$ Por tanto, el activismo judicial supondría ir más allá de la mera elección e interpretación de la

\footnotetext{
2. Si bien Bellei considera que la fragmentación se limita a representar «una tensión natural que debe soportar todo sistema que funciona con prescindencia de la regla del precedente, y que carece de una estructura institucional jerárquica»; y respecto a los conflictos de jurisdicción, son los Estados los que han de encargarse «de desarrollar ex ante reglas claras de delimitación de competencia, o bien de incluir herramientas jurídicas eficaces para enfrentar aquellos casos en los que se produce un inadecuado ejercicio de forum shopping o en los que pueden generarse múltiples procedimientos, sean éstos paralelos o sucesivos» (Bellei Tagle, 2016: 45).

3. Esto no quiere decir que debamos considerar ese proceso desde una perspectiva negativa, aunque ello demande el estudio, por ejemplo, de la legitimidad de esa actuación judicial. Los tribunales internacionales aportan un razonamiento jurídico que no pueden proveer los sistemas de arbitraje y que es imprescindible en el desarrollo del derecho internacional y de la función pro paz de los tribunales internacionales (Von Bogdandy y Venzke, 2012: 12).

4. Para el origen del concepto de activismo judicial, véase Kmiec (2004: 1.444-1.462)

5. Para las razones de esta división, véase Dworkin (1992: 150).
} 
norma aplicable a cada caso, para suponer una suerte de creación del derecho por parte de los jueces (making law). ${ }^{6}$

La traslación de este esquema a la comunidad internacional exige que los Estados se sometan a las decisiones de los tribunales a quienes confieren su jurisdicción y las cortes internacionales sometan su actividad al derecho producido por los propios Estados, pero la realidad se presenta mucho más compleja. No voy a adentrarme en la dificultad de trasladar concepciones propias de algunos sistemas jurídicos nacionales al ordenamiento jurídico internacional, en primer lugar porque son indiscutibles las particularidades del derecho internacional respecto de los ordenamientos internos. En segundo lugar, porque es generalmente aceptado que ningún derecho es lo suficientemente completo y preciso para no dejar margen al poder judicial, al menos en los llamados casos difíciles, en los que la resolución no es sencilla con el derecho existente (Dworkin, 1992: 147; Hart, 1961: 26). ${ }^{7}$

Lo cierto es que, como vimos antes, de manera formal el derecho internacional considera la jurisprudencia solo como medio auxiliar, sin capacidad para crear derecho, ${ }^{8}$ y desconoce la doctrina del precedente obligatorio, de modo que las decisiones judiciales son solo obligatorias para las partes en cada caso concreto. ${ }^{9}$ No obstante, en la práctica, los tribunales internacionales se erigen como las voces autorizadas de los principios y normas no escritas, y acaban traspasando la frecuente difusa línea que separa la interpretación de la creación del derecho. ${ }^{10}$ Podemos entonces preguntarnos por qué los Estados no reconocen ese papel real de los tribunales internacionales; es decir, por qué los Estados no reconocen expresamente a los tribunales internacionales el poder de crear derecho. Para Vogelfanger (2015: 258), parece razonable considerar que la respuesta a esa pregunta reside en el problema de legitimidad que ello acarrearía. Lo cierto es que los Estados rara vez hacen uso de su posición de intérpretes auténticos del derecho convencional, ni hacen esfuerzos destacados por frenar la importancia creciente de la jurisprudencia. De modo que en la medida en que los Estados no solo crean esos tribunales, sino que aceptan su

6. En ocasiones, principalmente en el ámbito constitucional (aunque sería ampliable a jurisdicciones como la de la Corte IDH), se distingue el activismo referido a la interferencia con el poder legislativo del que supone interferencia con la actividad de la administración (Lozada, 2018: 212).

7. Respecto no solo a la existencia, sino también la importancia del making law de los tribunales internacionales en el desarrollo del derecho internacional, véase Von Bogdandy y Venzke (2012: 12).

8. Artículo 38 del Estatuto de la Corte Internacional de Justicia, anexo a la Carta de la Organización de las Naciones Unidas, adoptado el 26 de junio de 1945.

9. Estatuto de la Corte Internacional de Justicia, artículo 59; artículo 68.1 de la Convención Americana sobre Derechos Humanos, suscrita el 22 de noviembre de 1969 en San José, Costa Rica.

10. The imperceptible process in which the judicial decision ceases to be an application of existing law and becomes a source of law for the future is almost a religious mystery into which it is unseemly to pry» (Lauterpacht, 1982: 21) («El proceso imperceptible en el que la decisión judicial deja de ser una mera aplicación de la ley existente y se convierte en una fuente legal para el futuro es casi un misterio religioso en el que es impropio indagar»; traducción libre del equipo editorial). 
labor están reconociendo, al menos por omisión, su actuación y, por tanto, los están legitimando. ${ }^{11}$

La apreciación del margen de libertad de los jueces de modo que acabe siendo etiquetado como activismo judicial es una cuestión de grado y depende en gran medida de los intereses y valores de quien está evaluando, principalmente porque casi siempre es un término que se usa con afán acusatorio, no elogioso y ni siquiera descriptivo. Por ello, y porque toda decisión judicial precisamente por serlo puede ser concebida como una solución legalmente válida, el activismo judicial depende en cada caso de las convenciones sociales sobre cuál es el papel adecuado del poder judicial, de modo que el activismo se produce cuando se traspasan los límites de dicho papel (Zarbiyev, 2012: 6).

En definitiva, contextualizar se vuelve imprescindible: en cada cultura jurídica se fijan unos límites a la función judicial. El activismo supondría traspasar dichos límites; sin embargo, no pueden fijarse en términos legales estrictos respecto al mayor o menor sometimiento a la norma, o la mayor o menor creatividad jurisprudencial, porque el ordenamiento jurídico no fija por sí mismo unas fronteras claras al respecto, y porque la actividad judicial en sí misma o sus productos son derecho. ${ }^{12}$ Por ello, no es difícil apreciar cómo se etiquetan como activismo judicial las decisiones que no gustan, y se aceptan como jurisprudencia legítima aquéllas que son acordes con la propia concepción.

\section{El activismo judicial internacional: La Corte IDH}

Muchas áreas del derecho internacional se han visto influidas por la casuística legal desarrollada por diversos tribunales internacionales. De hecho, la visión simplificada antes descrita del quehacer judicial como mero aplicador del derecho, ya inexacta en los derechos internos de los Estados (más aún si nos adentrásemos en la práctica del common law) es incluso más difícil de encajar en el ámbito del derecho internacional. En la medida en que la práctica de los tribunales internacionales ha extendido el alcance de su jurisdicción, se ha avivado el interés por las relaciones entre esos tribunales y los Estados que ven restringida su discreción debido a dicha actividad judicial. De modo que la doctrina iusinternacionalista ha de ocuparse cada vez más del activismo judicial.

11. «En la gran mayoría de los casos, los Estados aceptan, cumplen e internalizan lo señalado por los tribunales internacionales, $\mathrm{o}$ al menos no hay una crítica clara, concisa y elaborada coordinadamente entre los países para mostrar una seria preocupación al respecto» (Vogelfanger, 2015: 259).

12. Acogemos una definición amplia de derecho como el conjunto de los fenómenos reales que se identifican como sus referentes: «En primer lugar, las normas jurídicas [...] junto a las adicciones de los principios generales (de creación estatal, jurisprudencial o doctrinal) y doctrina (tanto jurisprudencial como profesoral); todas ellas vertebradas en el bloque teórico del ordenamiento jurídico. En segundo lugar, los actos jurídicos singulares y concretos, sean de procedencia administrativa judicial o privada y que forman parte del derecho aunque no sean ordenamiento jurídico. Y en tercer lugar, los hechos jurídicos [...] que son atraídos a la esfera del derecho por la fuerza de la gravedad de sus consecuencias jurídicas» (Nieto, 2007: 17). 
El Tribunal de Justicia de la Unión Europea (TJUE), ${ }_{13}^{13}$ el Tribunal Europeo de Derechos Humanos $(\mathrm{TEDH})^{14}$ y la Corte IDH han llamado especialmente la atención en la discusión sobre el activismo jurisprudencial internacional. La Corte se ha constituido en una de las jurisdicciones de referencia en materia de derechos humanos junto al Tribunal de Estrasburgo. Sin embargo, lo que para algunos ha supuesto grandes avances en la protección de los derechos de los ciudadanos de los Estados sujetos a su jurisdicción (Quispe Remón, 2016: 230-231), para otros son muestras de un activismo judicial que llega a atentar contra el Estado de derecho y la democracia. ${ }^{15}$ Llegados a este punto, no podemos evitar preguntarnos: ¿qué Estado de derecho, qué democracia? ¿Los de la comunidad internacional, los de los Estados? La crítica a un tribunal internacional a través de estos conceptos requeriría una explicación o precisión previa en este sentido, aunque ahora no vamos a detenernos en ello. ${ }^{16}$

Para adentrarnos en el análisis del papel de la Corte IDH desde esta perspectiva (y las críticas que ha recibido), hacemos uso del marco analítico propuesto por Zarbiyev y reorganizamos en tres grupos los elementos que él trabaja como favorecedores del activismo jurídico: por un lado, un grupo de elementos jurídico-estructurales; por otro, los elementos que podríamos considerar intrínsecos al propio tribunal; y, por último, un grupo que recoge los factores más extrínsecos al tribunal.

\section{Elementos jurídico-estructurales}

En este grupo vamos a centrarnos en elementos que derivan de las características de la propia construcción jurídica del tribunal y que son relevantes de cara a facilitar un mayor o menor activismo judicial: el grado de determinación del sistema, la existencia o no de un sistema judicial estructurado jerárquicamente, y la naturaleza del procedimiento.

\section{Grado de determinación del sistema}

Respecto del grado de determinación del sistema en el que opera el tribunal, Zarbiyev (2012: 8) considera que siempre existe un primer nivel en el que es necesario determinar qué consideramos derecho, y un segundo nivel en el que se procede a la interpretación

13. Véase, por ejemplo, el libro de Rasmussen (1986), y el comentario al éste de Cappelletti (2015).

14. Aunque en comparación con la Corte IDH el TEDH ha sido calificado de tribunal tímido (en el sentido de menos activista), el Tribunal Europeo también se muestra activista cuando ha de «juzgar casos que por su escala y/o violencia y/o sistematización tiene características similares a los casos juzgados por la Corte IDH», como por ejemplo ocurre con los casos contra Turquía ante el TEDH, en los que se observa una activismo similar al desarrollado por la Corte IDH (Ambos y Böhm, 2013: 1.081 y 1.084).

15. Posiblemente, los autores más señalados en ese sentido sean Malarino (2010: 61) y Gargarella (2016: 428-431).

16. En ese sentido, véase Candia-Falcón (2015: 229-230), que además de plantear sucintamente el papel del Estado de derecho en el derecho internacional, alaba la labor de la Corte para avanzar en los Estados de derecho de los Estados americanos, pero critica la debilidad del respeto a los mismos principios por parte de la Corte en el Sistema Interamericano. 
del derecho definido como tal en el primer nivel. Generalmente, en los derechos internos el primer nivel es menos conflictivo; en el derecho internacional ambos niveles pueden gozar de una gran indeterminación, lo que permite mayor discreción judicial.

Ya hemos hecho referencia a que las características propias del derecho internacional favorecen que el juez internacional no pueda ser un mero ejecutor de la norma:

En un sistema descentralizado sin un órgano legislativo o un proceso legislativo obligatorio, y donde el derecho no escrito se desarrolla a través del amorfo proceso de la práctica de los Estados y la opinio iuris, el proceso de decisión judicial tiene un gran peso en la determinación del derecho (Boyle y Chinkin, 2007: 268).

En este sentido, la Corte IDH se ha comportado con las características de lo que es: un tribunal internacional, aunque con sus particularidades. En concreto, en el caso de este tribunal, ha sido muy relevante la determinación del derecho que puede aplicar, más allá de la literalidad de lo contemplado en la Convención Americana sobre Derechos Humanos $(\mathrm{CADH})^{17} \mathrm{y}$ de los otros instrumentos que expresamente reconocen esa posibilidad: la Convención Interamericana para Prevenir y Sancionar la Tortura, ${ }^{18}$ la Convención Interamericana sobre Desaparición Forzada de Personas ${ }^{19}$ y el Protocolo Adicional a la Convención Americana sobre Derechos Humanos en Materia de Derechos Económicos, Sociales y Culturales ${ }^{20}$ para algunos de sus derechos.

Efectivamente, en ocasiones la Corte ha ampliado su conocimiento a otras convenciones de derechos humanos firmadas en el ámbito de la Organización de los Estados Americanos, y también ha introducido estándares internacionales del derecho internacional de los derechos humanos, además de acudir con frecuencia al derecho internacional general. Un ejemplo del primer proceso es la consideración de la Corte de su competencia para aplicar la Convención Interamericana para prevenir, sancionar

17. Artículo 62.3 de la Convención Americana sobre Derechos Humanos, adoptada en San José, Costa Roca, el 22 de noviembre de 1969 (vigente desde el 18 de julio de 1978).

18. Adoptada en Cartagena de Indias el 9 de diciembre de 1985, establece: «Una vez agotado el ordenamiento jurídico interno del respectivo Estado y los recursos que éste prevé, el caso podrá ser sometido a instancias internacionales cuya competencia haya sido aceptada por ese Estado» (artículo 8, párrafo final).

19. Adoptada en Belem Do Para el 9 de junio de 1994, establece: «Para los efectos de la presente Convención, el trámite de las peticiones o comunicaciones presentadas ante la Comisión Interamericana de Derechos Humanos en que se alegue la desaparición forzada de personas estará sujeto a los procedimientos establecidos en la Convención Americana sobre Derechos Humanos, y en los Estatutos y Reglamentos de la Comisión y de la Corte Interamericana de Derechos Humanos, incluso las normas relativas a medidas cautelares» (artículo 13).

20. Adoptado en San Salvador el 17 de noviembre de 1988, establece: «En el caso de que los derechos establecidos en el párrafo a) del artículo 8 y en el artículo 13 fuesen violados por una acción imputable directamente a un Estado parte del presente Protocolo, tal situación podría dar lugar, mediante la participación de la Comisión Interamericana de Derechos Humanos, y cuando proceda de la Corte Interamericana de Derechos Humanos, a la aplicación del sistema de peticiones individuales regulado por los artículos 44 a 51 y 61 a 69 de la Convención Americana sobre Derechos Humanos» (artículo 19.6). 
y erradicar la violencia contra la mujer, ${ }^{21}$ tras interpretar que al atribuir competencia a la Comisión respecto del artículo 7 de dicho tratado ${ }^{22}$ y no exceptuar su aplicación de los requisitos y procedimientos para las comunicaciones individuales, está otorgando competencia a la Corte respecto de dicha Convención. ${ }^{23}$

En relación con la introducción de normas de derechos humanos provenientes del ámbito universal, destaca el caso del recurso a la Convención sobre los Derechos del Niño ${ }^{24}$ para complementar y precisar el contenido del artículo 19 de la Convención. ${ }^{25}$ En ese sentido, la Corte ha afirmado que

al dar interpretación a un tratado no solo se toman en cuenta los acuerdos e instrumentos formalmente relacionados con éste (inciso segundo del artículo 31 de la Convención de Viena), sino también el sistema dentro del cual se inscribe (inciso tercero del artículo 31). ${ }^{26}$

Tanto la Convención Americana como la Convención sobre los Derechos del Niño forman parte de un muy comprensivo corpus juris internacional de protección de los niños que debe servir a esta Corte para fijar el contenido y los alcances de la disposición general definida en el artículo 19 de la Convención Americana (párrafo 194).

Esta introducción de estándares internacionales en su jurisprudencia también ha supuesto que la Corte IDH haga referencia a normas de soft law como múltiples protocolos y principios que existen en el derecho internacional de los derechos humanos, ${ }^{27}$ y a la jurisprudencia del Tribunal Europeo de Derechos Humanos y los comités de tratados de derechos humanos de Naciones Unidas.

Es importante señalar que el derecho internacional de los derechos humanos es claro respecto al carácter universal de los derechos humanos y el deber de los Esta-

21. Adoptada en Belém Do Pará, Brasil, el 9 de junio de 1994 (vigente desde el5 de marzo de 1995)

22. Artículo 12 de la Convención Interamericana para Prevenir, Sancionar y Erradicar la Violencia contra la Mujer, 1994.

23. Sentencia de excepción preliminar del caso González y otras ( Campo Algodonero») con México, Corte Interamericana de Derechos Humanos, fondo, reparaciones y costas, serie c 205, 16 de noviembre de 2009, párrafos 35-77 (en especial, párrafos 41, 54, 55 y 58), disponible en https://bit.ly/1kho5vc.

24. Adoptada por la Asamblea General de Naciones Unidas en su Resolución 44/25, del 20 de noviembre de 1989 (vigente desde el 2 de septiembre de 1990).

25. «Todo niño tiene derecho a las medidas de protección que su condición de menor Requieren por parte de su familia, de la sociedad y del Estado.» (Convención Americana sobre Derechos Humanos, 1969: Artículo 19)

26. Sentencia de fondo del caso «Niños de la calle» (Villagrán Morales y otros) con Guatemala, Corte Interamericana de Derechos Humanos, Serie c 63, 1999, párrafo 192, disponible en https://bit.ly/2btrpXM. En ella cita la Opinión Consultiva OC-16/99, serie a 16 de la Corte IDH, «El derecho a la información sobre la asistencia consular en el marco de las garantías del debido proceso legal», 1 de octubre de 1999, párrafos 84, 124 y 137, disponible en https://bit.ly/2d5eMBp, en la que utilizó una técnica equivalente para interpretar la CADH, complementándola en especial con el Pacto Internacional de Derechos Civiles y Políticos y la Convención de Viena sobre Relaciones Consulares.

27. Para ver una relación de este tipo de documentos utilizados por la Corte IDH, véase Núñez Marín (2014: 213-214). 
dos, sean cuales fueren sus sistemas políticos, económicos y culturales, de promover y protegerlos, ${ }^{28}$ labor en la que los acuerdos regionales desempeñan un papel fundamental reforzando las normas universales de derechos humanos contenidas en los instrumentos internacionales. ${ }^{29}$

Expresión de esa misma labor interpretativa extensiva y pro homini de la Corte IDH son la creación de «nuevas» reglas, la ampliación del contenido de los derechos de la Convención o incluso la «creación» de derechos nuevos. En el primer sentido podríamos encontrar, entre otras, la prohibición de amnistiar graves violaciones de derechos humanos; ${ }^{30}$ restricción de la aplicación del ne bis in idem en caso de nuevas pruebas; ${ }^{31} \mathrm{o}$ la limitación del principio de irretroactividad de la ley penal..$^{32}$

Serían nuevos derechos, entre otros, el de los familiares de las víctimas a la verdad (incluso la consideración del familiar en un nuevo concepto de víctima), y el derecho a la verdad ligado a la efectiva sanción penal a través de los tribunales; ${ }^{33}$ el derecho del detenido extranjero a obtener información sobre la asistencia consular; ${ }^{34}$ el derecho a la propiedad comunal indígena; ${ }^{35} \mathrm{y}$ el derecho de acceso a la identidad biológica de los progenitores..$^{36}$

Para quienes defienden la labor de la Corte, sin embargo, este activismo supone cumplir con «el objetivo de reconocimiento de los derechos más allá de las fronteras del formalismo jurídico y son necesarias para alcanzar una sociedad igualitaria y basada en la justicia social» (Núñez Marín, 2014: 215).

28. Declaración y Programa de Acción de Viena, 1993, párrafos 1 y 5, sección 1, Naciones Unidas, Resolución de la Asamblea General 48/141 del 20 de diciembre de 1993, artículo 3, letras a) y b).

29. Declaración y Programa de Acción de Viena, 1993, párrafo 37, sección 1.

30. Sentencia de fondo del caso Barrios Altos con Perú, Corte Interamericana de Derechos Humanos, serie c 75, 14 de marzo de 2001, párrafos 44 y 51, apartado 4, disponible en https://bit.ly/VMcop4. Más recientemente: sentencia de fondo y reparaciones del caso Gelman con Uruguay, Corte Interamericana de Derechos Humanos, serie c 221, 24 de febrero de 2011, párrafos 230 y ss., disponible en https://bit. ly/1iIziUS. Respecto al activismo o no de la Corte IDH sobre el desconocimiento de los efectos jurídicos de las leyes de amnistía, véase Villanueva Flores (2018: 155-156).

31. Corte Interamericana de Derechos Humanos, Serie C No. 154 "Caso Almonacid Arellano y otros Vs. Chile», de 26 de septiembre de 2006: principalmente párrafo 154. Disponible en: https://bit.ly/1wlXjLP

32. Sentencia de excepciones preliminares, fondo, reparaciones y costas del caso La Cantuta con Perú, Corte Interamericana de Derechos Humanos, serie c 162, 29 de noviembre de 2006, párrafo 226, disponible en https://bit.ly/2nRQYXQ.

33. Sentencia de fondo del caso Velásquez Rodríguez con Honduras, Corte Interamericana de Derechos Humanos, serie C 4, 29 de julio de 1988, párrafo 181, disponible en https://bit.ly/1wlRorL. sentencia de excepciones preliminares, fondo, reparaciones y costas del caso Almonacid Arellano y otros con Chile, Corte Interamericana de Derechos Humanos, serie c 154, 26 de septiembre de 2006, párrafos 147-150, disponible en https://bit.ly/1wlXjLP. Véase al respecto Ferrer Mac-Gregor (2016: 156-158).

34. Opinión Consultiva OC-16/99 serie a 16, párrafo 141.

35. Sentencia de fondo, reparaciones y costas del caso Comunidad Mayagna (Sumo) Awas Tingni con Nicaragua, Corte Interamericana de Derechos Humanos, serie c 79, 31 de agosto de 2001, párrafo 148, disponible en https://bit.ly/1tQVZoo.

36. Sentencia de fondo y reparaciones del caso Gelman con Uruguay, párrafo 122. 
Ciertamente, no es lo mismo precisar el contenido de una norma que consideramos que es fuente del ordenamiento jurídico pero que por su propia naturaleza necesita concreción, como es la costumbre internacional, que incrementar el número de fuentes a tener en cuenta en la resolución de los conflictos. Sin embargo, la Corte puede defender, y lo hace con su jurisprudencia, la unidad del derecho internacional de los derechos humanos, la suerte de un orden público superior a la voluntad de los Estados en esta materia. El que fuera juez de la Corte, Antônio A. Cançado Trindade, lo expresaba así en un voto particular:

La interpretación y aplicación de los tratados de derechos humanos ha sido guiada por las consideraciones de un interés general superior u ordre public que trasciende los intereses individuales de las partes contratantes. [...] La rica jurisprudencia sobre métodos de interpretación de los tratados de derechos humanos ha mejorado la protección del ser humano a nivel internacional y ha enriquecido el derecho internacional bajo el impacto del derecho internacional de derechos humanos [...]. El trabajo de los Tribunales Interamericanos y Europeos de Derechos Humanos sin duda ha contribuido a la creación de un ordre public internacional basado en el respeto por los derechos humanos en cualquier circunstancia. ${ }^{37}$

La idea que subyace a estos razonamientos y gana cada vez más fuerza es la de que el derecho de los derechos humanos forma un sistema integral, universal (Medina, 2013: 652). Sobre ello volveremos más adelante al tratar la concepción que los jueces tienen de la función de la Corte IDH como tribunal internacional de derechos humanos.

\section{Estructuración jerárquica del sistema judicial}

Es también una diferencia fundamental de los tribunales internacionales respecto de los tribunales internos y que favorece su discrecionalidad, la inexistencia de un sistema judicial estructurado jerárquicamente. Es decir, en el derecho internacional cada tribunal es un sistema judicial en sí mismo, de modo que es imposible recurrir, por falta de instancia superior para ello, aquellas decisiones que se consideren fruto de un ejercicio inapropiado de la función judicial. Es obvio que esa condición de instancia última incrementa el espacio de discrecionalidad de los jueces internacionales (Zarbiyev, 2012: 14).

En el caso de la Corte IDH no solo se configura como instancia única, sino también como última instancia en materia de derechos humanos de los sistemas judiciales de los Estados parte a través del desarrollo del control de convencionalidad:

La Corte es consciente de que los jueces y tribunales internos están sujetos al imperio de la ley y, por ello, están obligados a aplicar las disposiciones vigentes en el ordenamiento jurídico. Pero cuando un Estado ha ratificado un tratado internacional como la

37. Sentencia del caso Caesar con Trinidad y Tobago, Corte Interamericana de Derechos Humanos, serie c 123, 2005, voto razonado del juez Antônio A. Cançado Trindade, párrafos 6 y 7, disponible en https://bit. ly/2cRwlXM. 
Convención Americana, sus jueces, como parte del aparato del Estado, también están sometidos a ella, lo que les obliga a velar por que los efectos de las disposiciones de la Convención no se vean mermadas por la aplicación de leyes contrarias a su objeto y fin, y que desde un inicio carecen de efectos jurídicos. En otras palabras, el Poder Judicial debe ejercer una especie de «control de convencionalidad» entre las normas jurídicas internas que aplican en los casos concretos y la Convención Americana sobre Derechos Humanos. En esta tarea, el Poder Judicial debe tener en cuenta no solamente el tratado, sino también la interpretación que del mismo ha hecho la Corte Interamericana, intérprete última de la Convención Americana. ${ }^{38}$

Se trata, por tanto, de la doctrina desarrollada por la Corte según la cual los tribunales nacionales han de revisar la compatibilidad de las normas nacionales con la CADH en el momento de aplicarlas. Al hacerlo debe atenderse a la propia interpretación de la $\mathrm{CADH}$ hecha por la Corte, tanto en los casos contenciosos como en las opiniones consultivas, al resolver sobre medidas provisionales, supervisión de cumplimiento de sentencias, etcétera (Corte IDH, 2015).

En este caso, la Corte IDH es criticada por configurar un modelo de revisión sobre la base de un sistema de precedente obligatorio que no estaba previsto en la $\mathrm{CADH} ;{ }^{39}$ se destaca su incompatibilidad con el principio de legalidad, la falta de claridad de la jurisprudencia como fuente de derecho frente a la norma legal, y la imprecisión de sus aspectos procedimentales (Candia-Falcón, 2015: 245). Sin embargo, hemos de observar que desde la perspectiva del derecho internacional, la autoridad de la jurisprudencia de un tribunal internacional para los Estados que se han sometido al mismo es inequívocamente derecho, y que como tal obliga a todos los poderes de éste. La sentencia concreta obliga a las partes, pero la interpretación que en ella se hace del derecho que aplica trasciende a ese proceso. ${ }^{40}$

Por otro lado, también es interesante tener en cuenta aquí que la interpretación del principio de agotamiento de los recursos internos que ha hecho la Corte, por su naturaleza un tribunal subsidiario, merma el contralímite de dicho agotamiento previo. El artículo 46.2 de la CADH contempla tres excepciones al principio de agotamiento del sistema de recursos internos al acceso al sistema interamericano de derechos humanos (SIDH): que no exista en la legislación interna del Estado de que se trata el debido proceso legal para la protección del derecho o derechos que se alega han sido violados; que no se haya permitido al presunto lesionado en sus derechos el acceso a los recursos de la jurisdicción interna, o haya sido impedido de agotarlos; y que haya retardo injustificado en la decisión sobre los mencionados recursos. A estos, la Corte ha añadido

38. Sentencia del caso Almonacid Arellano y otros con Chile, párrafo 124.

39. «Los Estados parte en la Convención se comprometen a cumplir la decisión de la Corte en todo caso en que sean partes.» (artículo 68.1).

40. «Existe un doble efecto de las sentencias de la Corte Interamericana: el de cosa interpretada que tiene una eficacia erga omnes y el de cosa juzgada que únicamente tiene efectos inter partes» (Rodríguez Rescia, 1997: 16). 
la situación de imposibilidad de obtener asistencia legal por impedirlo la situación de indigencia (al vincular el 46.2 con los artículos 1.1, 24 y 8 de la CADH) o el temor generalizado de los abogados del país. ${ }^{41}$

Es decir, la Corte IDH no solo comparte la característica de los tribunales internacionales de carecer de una instancia superior, sino que ha reforzado su posición de tribunal «superior» respecto de los poderes judiciales de los Estados miembros en un contexto de desconfianza hacia los órganos de los Estados parte sobre su capacidad para garantizar los derechos humanos (Viana Garcés, 2008: 45). Así, hace explícita y enfatiza la primacía de su jurisprudencia e interpretaciones en materia de derechos humanos respecto a los Estados parte con el control de convencionalidad, y facilita su acceso suavizando el principio de subsidiariedad a partir del uso frecuente y amplio de las excepciones al principio de agotamiento de los recursos internos.

\section{Naturaleza del procedimiento}

En el ámbito procedimental, Zarbiyev (2012: 25) resalta diversos elementos como favorecedores del activismo judicial. La existencia de procedimientos consultivos, además de los jurisdiccionales, permite esperar que los jueces sean más proclives al activismo, porque se trata de decisiones que guardan menos confrontación y que generan menos preocupaciones sobre su implementación. También puede ser importante el carácter permanente del tribunal, el modo de su acceso, y la forma de implementación de sus decisiones finales, de manera que la libertad de los jueces aumenta en la medida en que disminuye su dependencia de los Gobiernos en cada uno de estos momentos procedimentales.

Respecto a la primera cuestión, la Corte ejerce también la función consultiva y le ha dado tal importancia que la incluye en el material interpretativo al que ha de atenderse en el control de convencionalidad. Así, el costarricense Manuel Ventura Robles, años atrás juez de la Corte, lo especifica claramente:

En uso de su función jurisdiccional, la Corte declara la verdad de los hechos en un caso concreto que es exigible al Estado parte responsable, mientras que la función consultiva responde a preguntas hipotéticas cuyas respuestas no pueden ser ejecutadas, pese a que son obligatorias por constituir una interpretación de la Convención, hecha por el órgano jurisdiccional que dispone la propia Convención (Ventura Robles, 2002: 274).

Si bien es menor que la función contenciosa desde una perspectiva cuantitativa, ${ }^{42}$ la función consultiva es importante por diversas razones. Primero, porque está abier-

41. Opinión Consultiva OC-1119o, «Excepciones al agotamiento de los recursos internos (artículos 46.1, 46.2.a y 46.2.b Convención Americana de Derechos Humanos)», Corte Interamericana de Derechos Humanos, serie a 11, 10 de agosto de 1990, párrafos 31 y 33.

42. Al final de 2017 la Corte IDH había dictado más de 340 sentencias, y emitido más de una veintena de opiniones consultivas. Véase Corte Interamericana de Derechos Humanos (2018b). 
ta a todos los Estados miembros de la OEA y a los órganos principales de la misma: la Comisión Interamericana de Derechos Humanos, la Asamblea General, el Consejo Permanente, la Comisión Interamericana de Mujeres, etcétera.

Segundo, porque la función consultiva no solo permite interpretar la $\mathrm{CADH}$, sino que la Corte puede ejercerla,

en general, sobre toda disposición, concerniente a la protección de los derechos humanos, de cualquier tratado internacional aplicable en los Estados americanos, con independencia de que sea bilateral o multilateral, de cuál sea su objeto principal o de que sean o puedan ser partes del mismo Estados ajenos al sistema. ${ }^{43}$

Además, permite que la Corte se pronuncie sobre la compatibilidad del derecho interno de los Estados con las obligaciones que manan de la CADH (artículo 64).

La Corte IDH no es un tribunal permanente, ni por la periodicidad de sus sesiones ${ }^{44}$ ni por el estatuto de sus jueces. De acuerdo a su estatuto, ${ }^{45}$ sus jueces no cobran salario, sino emolumentos y dietas de viaje (artículo 17), y no tienen la obligación de residir en la sede, sino estar a disposición y trasladarse a la Corte de acuerdo con sus obligaciones (artículo 16); por tanto, se les exige un sistema limitado de incompatibilidades (artículo 18).

En íntima relación con la falta de permanencia de la Corte está el hecho de que los particulares no pueden recurrir directamente ante ella, sino que deben acudir primero a la Comisión Interamericana de Derechos Humanos, que es la que puede presentar, además de los Estados, demandas ante la Corte. Sin embargo, las sucesivas modificaciones de los Reglamentos de la Comisión y la Corte han impulsado el papel de los particulares. Actualmente, la Comisión ha visto reducida su discrecionalidad respecto a presentar un caso ante la Corte, pues debe hacerlo prácticamente siempre que el Estado no haya cumplido sus recomendaciones..$^{46}$ Los particulares pueden presentar direc-

43. Opinión Consultiva OC-1/82, «"Otros tratados” objeto de la función consultiva de la Corte (artículo 64 Convención Americana sobre Derechos Humanos)», Corte Interamericana de Derechos Humanos, serie a 1, 24 de septiembre de 1982.

44. En 2017 ha celebrado tres sesiones ordinarias, sumando menos de seis semanas de duración, y dos periodos extraordinarios de una semana cada uno - similar a como viene funcionando desde 2002(véase «Fechas de sesiones anteriores», Corte Interamericana de Derechos Humanos, disponible en http:// bit.ly/2 $\left.\mathrm{A}_{3} \mathrm{Hy} 2 \mathrm{v}\right)$. Para 2018, la Corte IDH prevé que «las reuniones colegiadas de los jueces y jueza lleguen a catorce semanas, financiadas por el fondo regular en comparación con las ocho semanas de años anteriores, dejándose fuera únicamente un mes sin sesionar. Un récord en la historia de nuestra Corte y que nos muestra la tendencia a una estabilidad e institucionalidad, todo esto con la perspectiva de tener jueces de dedicación exclusiva y permanente» (Corte IDH, 2018: 9).

45. Aprobado mediante Resolución 448, adoptada por la Asamblea General de la OEA en su noveno periodo de sesiones, celebrado en La Paz, Bolivia, octubre de 1979. Modificado en 1982, mediante AG/RES. 625 (XII-o/82), y en 1991, por AG/RES. 1098 (XXI-91).

46. Artículo 45.1 del Reglamento de la Comisión Interamericana de Derechos Humanos, 2009, aprobado por la Comisión en su 137 período ordinario de sesiones, celebrado del 28 de octubre al 13 de noviembre de 2009. También se ha visto afectado el papel de la Comisión en el procedimiento ante la Corte en la 
tamente alegaciones autónomas en el proceso: primero se les reconoció en la etapa de reparaciones y, posteriormente, durante todo el proceso. ${ }^{47}$ Además, en 2008, la Asamblea General de la OEA dispuso la creación del Fondo de Asistencia Legal del Sistema Interamericano de Derechos Humanos (para facilitar el acceso a quienes no cuentan con recursos suficientes), y en la modificación del reglamento de noviembre de 2009 se creó la figura del defensor interamericano, que puede ser designado de oficio por la Corte para que represente a las presuntas víctimas sin representación legal debidamente acreditada durante la tramitación del caso (artículo 37).

Por último, respecto de las sentencias de la Corte y su sistema de implementación, hay que partir de dos datos importantes. En primer lugar, que se trata de sentencias obligatorias pero que carecen de valor ejecutivo salvo lo referido al contenido indemnizatorio, ${ }^{48}$ de modo que los Estados cuentan con un amplio margen de discrecionalidad para su ejecución en el ámbito interno. En segundo lugar, que las medidas ordenadas por la Corte en sus sentencias se han constituido en uno de los flancos principales de la crítica por activismo.

La labor desarrollada por la Corte IDH se enmarca, como no podría ser de otro modo, en la realidad de los Estados americanos. Con las dictaduras se producían violaciones masivas de derechos humanos. Con la llegada de las democracias, los problemas de diseño institucional y de cultura social llevan a violaciones generalizadas de derechos humanos de determinados grupos. Como explica Viana Garcés (2008: 45), debido a ello los órganos del SIDH desarrollan una relación con los Estados parte basada en la desconfianza sobre su capacidad para lograr verdaderas garantías de los derechos humanos. Lo cual ha supuesto una interpretación distinta del principio de subsidiariedad propio del derecho internacional ${ }^{49}$ y la extensión de sus facultades de control por parte de la Corte IDH, adoptando decisiones jurisdiccionales que suponen ordenar las medidas exactas que deben adoptar los Estados para reparar las vulneraciones cometidas (en contraste con las autorrestricciones del Tribunal Europeo de Derechos Humanos).

En teoría, la Corte IDH habría de conocer de violaciones individuales de derechos humanos en contextos de Estado de derecho en los que los Estados firmantes de la Convención de San José propenderían al cumplimiento de las obligaciones internacionales de derechos humanos. En la realidad, encontramos la existencia de violaciones masivas y sistemáticas que presentan un fuerte componente estructural. El Estado puede no desarrollar una política de violaciones como en las dictaduras, pero sí permite, a través de sus prácticas culturales y estructuras institucionales, las violaciones masivas

última reforma del reglamento de la Corte IDH, de noviembre de 2009, para otorgar más protagonismo al litigio entre los representantes de las víctimas o presuntas víctimas y el Estado demandado.

47. Artículo 23 del Reglamento de la Comisión Interamericana de Derechos Humanos, el que fuera modificado por las reformas de 1996 y de 2000 , respectivamente.

48. «La parte del fallo que disponga indemnización compensatoria se podrá ejecutar en el respectivo país por el procedimiento interno vigente para la ejecución de sentencias contra el Estado» (artículo 68.2).

49. «La regla del agotamiento de los recursos internos [...] ha sido construida en el SIDH de manera negativa, es decir a partir de sus excepciones» (Viana Garcés, 2008: 46). 
de derechos humanos de ciertos grupos vulnerables (las mujeres, los migrantes, las personas privadas de libertad, los indígenas y las comunidades campesinas) (González Le Saux y Nash Rojas, 2011: 24). Ante esta situación, la Corte ha desarrollado un sistema de reparaciones de violaciones estructurales que implica una ampliación de la idea de reparación, más allá de las víctimas concretas del caso. Es decir, el mecanismo de los casos individuales ha servido para plantear temas de discriminación estructural, buscando soluciones generales a dichos problemas (medidas de garantía de no repetición, reparaciones transformadoras) (Martinón Quintero, 2016: 27).

Este activismo es defendido por quienes consideran que estas medidas establecidas por la Corte son imprescindibles en la consecución de la garantía de los derechos de la $\mathrm{CADH}$ en el contexto sociocultural y político de los Estados parte. Es ese sentido se ha afirmado:

El trabajo que viene desarrollando la Corte Interamericana de Derechos Humanos forma la columna vertebral en la protección de los derechos humanos en el continente, también forma parte importante en el desarrollo de las instituciones, sean políticas o jurisdiccionales, involucradas en la defensa y protección de los derechos humanos en el continente americano (Odimba-On'Etambalako, 2006: 704).

En concreto, para la propuesta del ius constitutionales commune de América Latina supondría la aportación internacional regional al intento de asegurar la normatividad y la implementación de las disposiciones constitucionales de los Estados de la región de cara a poner fin a las grandes injusticias, la violencia y la exclusión de los grupos desfavorecidos (Von Bogdandy, 2015: 15 y 18).

Sin embargo, al mismo tiempo, es fuertemente criticado por quienes ven una intromisión de la Corte IDH en la esfera de la soberanía de los Estados parte, especialmente al ordenar la derogación o sanción de leyes o normas constitucionales, revisión de decisiones judiciales y ordenación de políticas públicas, que quedarían muy lejos de lo dispuesto en el artículo 63 de la CADH..$^{\circ}$

Lo cierto es que el cumplimiento de las sentencias de la Corte por parte de los Estados depende en gran medida del tipo de medida de que se trata. Se cumple, principalmente, con la reparación económica, se siguen bastante las reformas legislativas y se incumple con las medidas de investigación penal (Abramovich, 2009: 26). De modo que, a finales de 2017, la Corte tiene archivados 26 casos en la lista de casos en etapa de supervisión archivados por cumplimiento, por considerar completamente cumplidas sus sentencias; mientras que se contabilizan $186^{51}$ casos que se mantienen en la lista de casos en etapa de supervisión por su incumplimiento total o parcial. El mecanismo más

50. Para un recopilatorio jurisprudencial de todo ello, véase Malarino (2010: 53-55).

51. La Corte IDH diferencia, dentro de los 186 casos, 15 en la lista de casos en etapa de supervisión en los cuales se ha aplicado el artículo 65 de la Convención y la situación constatada no ha variado. Véase «Casos en etapa de supervisión», Corte Interamericana de Derechos Humanos, disponible en http://bit. ly/2zYzVdB. 
efectivo de la Corte para lograr el cumplimiento de las sentencias son tanto las audiencias de supervisión internacional como las audiencias de seguimiento ante la Comisión o la Corte, ${ }^{52}$ pues la inclusión de los casos de incumplimiento en el informe anual que la Corte IDH remite a la Asamblea de la OEA supone solo una desaprobación moral. ${ }^{53}$

\section{Factores intrínsecos del tribunal}

Se trata de ver aquí aspectos intrínsecos al propio tribunal, como son la concepción que los propios jueces tienen de su función, su uso de doctrinas prudenciales respecto de su relación con otros poderes políticos (en este caso, principalmente los Estados) y las constricciones discursivas que pueden asumir los propios tribunales.

\section{Concepción que los propios jueces tienen de su función}

En este parámetro, Zarbiyev (2012: 11) considera que si los jueces se ven a sí mismos como meros «solucionadores» de conflictos desarrollarán una jurisprudencia menos ambiciosa que si se ven desempeñando funciones más amplias proveyendo de significado valores públicos, como servidores de la comunidad. Se trata, por tanto, de una variable muy subjetiva que dependerá de atributos personales de los jueces y de la formación de los tribunales (más o menos homogéneos culturalmente), pero también de cuestiones más estructurales como el contexto sociopolítico en el que desarrollan su labor, y la materia del derecho internacional de la que conozca la Corte (no parece casualidad que dos de los tres tribunales considerados más activistas sean tribunales de derechos humanos).

La composición de la Corte IDH es bastante homogénea. Todos sus jueces han de ser juristas y casi todos son latinoamericanos (solo uno de siete es elegido por las islas caribeñas anglohablantes), lo que hace que

La Corte tenga un fuerte sentido de unidad, y su jurisprudencia tenga un claro acento latinoamericano. Muchos de sus jueces tienen un pasado ligado a la defensa de los derechos humanos. La trayectoria de la Corte como un todo, y de ciertos jueces en particular, demuestra que de manera constante se ha sentido la necesidad de aplicar la $\mathrm{CADH}$ tan creativamente como fuese posible para contrarrestar las tendencias autoritarias de quienes han gobernado el continente y la tendencia de la sociedad de mantener los privilegios determinantes de discriminación (Medina, 2013: 662).

52. La referencia a esta supervisión fue expresamente incluida en el reglamento de la Corte IDH en su reforma de noviembre de 2009 al introducirla en su artículo 69, aunque se llevan a cabo desde 2007, e incluyen visitas in situ desde 2015 (Corte IDH, 2017: 20).

53. «La Corte someterá a la consideración de la Asamblea General de la Organización en cada periodo ordinario de sesiones un informe sobre su labor en el año anterior. De manera especial y con las recomendaciones pertinentes, señalará los casos en que un Estado no haya dado cumplimiento a sus fallos» (artículo 65 de la Convención Americana sobre Derechos Humanos). 
Efectivamente, es imprescindible tener en cuenta que muchos países de América Latina se incorporaron al SIDH en la etapa de las transiciones a la democracia precisamente para intentar protegerse de tentaciones autoritarias asiendo sus sistemas políticos y legales al ámbito internacional (Abramovich, 2009: 24). En la medida en que esas transiciones no han podido acabar con sistemas estructurales que conllevan y dejan impunes violaciones de derechos, no es difícil imaginar cómo todo ello ha marcado la concepción que los jueces tienen de su función.

También es fundamental el hecho de que la Corte IDH sea un tribunal de derechos humanos. Como explica Medina (2013: 653-654, 662-663), quien fue jueza de la Corte, si bien el derecho de los tratados indica que la interpretación judicial ha de comenzar por la literalidad de la norma, ${ }^{54}$ hay que tener en cuenta que el derecho internacional de los derechos humanos está formulado invariablemente como principios y normas generales que requieren necesariamente un desarrollo posterior al aplicarlos a circunstancias concretas. De modo que la elaboración, concreción y desarrollo de la norma no supone exceder la función judicial correspondiente, y debe hacerse siempre en atención al objeto y fin de los tratados, como interpretación pro persona. En concreto, la autora defiende el uso de las siguientes reglas de interpretación que considera generalmente aceptadas: la concepción de la $\mathrm{CADH}$ como «instrumento vivo», de modo que su interpretación ha de tener en cuenta los cambios y las condiciones presentes de cada caso; que la Corte aplique el corpus iuris del derecho internacional de los derechos humanos, ${ }^{55}$ de modo que interprete la CADH en el contexto de la evolución de los derechos humanos en el derecho internacional contemporáneo; y el uso del «efecto útil» de cara a encontrar la interpretación correcta para proveer de eficacia sus provisiones de cara al fortalecimiento de la democracia, que debido al contexto en el que ejerce su labor, es el objetivo expreso de la Corte.

\section{Existencia de doctrinas prudenciales}

Es frecuente que en los ámbitos intraestatales se desarrollen doctrinas sobre la relación del Poder Judicial con los otros poderes que suponen una limitación al poder de los jueces, de modo que éstos se abstengan de interferir en cuestiones políticamente sensibles. El hecho de que en el derecho internacional no exista una separación clara de poderes parece ser la razón por la que no hay una doctrina equivalente en el ámbito internacional. Zarbiyev (2012: 14) considera que lo más cercano a una doctrina prudencial en el ámbito del derecho internacional es la teoría del margen nacional de apreciación desarrollada por el TEDH.

54. «Un tratado deberá interpretarse de buena fe conforme al sentido corriente que haya de atribuirse a los términos del tratado en el contexto de estos y teniendo en cuenta su objeto y fin» (artículo 31.1 del Convenio de Viena sobre el Derecho de los Tratados).

55. «Conjunto de instrumentos internacionales de contenido y efectos jurídicos variados (tratados, convenios, resoluciones y declaraciones)» (Opinión Consultiva OC-16/99, párrafo 115. Desarrollado en el voto concurrente del juez Antônio A. Cançado Trindade, disponible en https://bit.ly/2d5eMBp). 
El margen de apreciación supone una deferencia por parte del tribunal internacional a favor de los Estados al permitirles ciertos ámbitos de discreción en la interpretación de los derechos recogidos en las correspondientes convenciones cuando no existe consenso entre los Estados parte sobre determinada cuestión, y parece adecuado considerar que las autoridades nacionales se encuentran en una posición mejor, más cercana, para determinar las restricciones de los derechos correspondientes. Tiene su fundamento en la diversidad cultural y jurídica de los Estados (García Roca, 2007: 130) y por la lógica de la subsidiariedad que se predica de toda jurisdicción internacional (Pascual Vives, 2013); ${ }^{56}$ pero en tanto argumento de confianza requiere que los Estados sobre los que se ejerza la jurisdicción estén constituidos como Estados de derecho y funcionen como democracias (Barbosa Delgado, 2013: 1.096).

Merece ser destacado que el margen de apreciación es, precisamente, una construcción judicial. Si la restricción de un derecho está fijada directamente en el propio precepto no estamos ante esta institución (Sánchez-Molina, 2016: 228). De hecho, hay quienes han considerado en el ámbito del TEDH que, debido a su escasa elaboración de este concepto, se deja tanto margen para la propia apreciación judicial en cada caso, que acaba resultando más una muestra de discrecionalidad y activismo judicial que de contención. ${ }^{57}$

Ampliamente usado por el TEDH, el margen de apreciación nacional no tiene la misma presencia en la jurisprudencia de la Corte IDH. Este tribunal tampoco ha definido esta doctrina, pero en algunos casos la ha introducido en su argumentación jurídica, por ejemplo, respecto del recurso ordinario eficaz, ${ }^{58} \operatorname{los}$ derechos políticos ${ }^{59} \mathrm{O}$ la libertad de expresión. ${ }^{60}$

Hay que tener en cuenta que una de las explicaciones que se ha dado del hecho de que en la jurisprudencia americana se haya llevado a cabo un uso menos prolífico del margen de apreciación nacional reside en que los primeros casos sustanciados ante la Corte IDH versasen sobre derechos que conforman el núcleo duro del derecho internacional de los derechos humanos (derecho a la vida, integridad personal, prohibición de

56. Pascual Vives sitúa el consenso como elemento clave para que un tribunal se decante por hacer uso o no del margen de apreciación nacional, dentro del consensualismo propio del derecho internacional.

57. «La Corte europea ejerce una discrecionalidad judicial en la que no se percibe con seguridad el motivo por el cual ha de respetar la solución nacional» (García Roca, 2007: 142). En sentido similar, Pascual Vives (2013: 225), aunque en su trabajo intenta buscarle una sistematicidad.

58. Sentencia de excepciones preliminares, fondo, reparaciones y costas del caso Herrera Ulloa con Costa Rica, Corte Interamericana de Derechos Humanos, serie c 107, 2 de julio de 2004 párrafo 161, disponible en https://bit.ly/1cUfkCo.

59. Sentencia de excepciones preliminares, fondo, reparaciones y costas del caso Casteñeda Gutman con México, Corte Interamericana de Derechos Humanos, serie c 104, 6 de agosto de 2008, párrafos 162, 166 y 205, disponible en https://bit.ly/2E04W46.

6o. Sentencia de excepciones preliminares, fondo, reparaciones y costas del caso Perozo y otros con México, Corte Interamericana de Derechos Humanos, serie c 194, 28 de enero de 2009, párrafos 166 y 117, disponible en https://bit.ly/291PNis. 
la tortura y ejercicio de la libertad personal) y que, por tanto, se encuentran más alejados del ámbito de aplicación de la noción del margen de apreciación nacional (Pascual Vives, 2013: 222).

\section{Las constricciones discursivas}

Todos los espacios discursivos, incluido el judicial, están sujetos a constricciones. Zarbiyev (2012: 29-30) considera que los jueces rara vez admiten su papel de hacederos de derecho, y que impelidos a preservar la expresión de su legitimidad, se autoaplican una poderosa constricción sobre su activismo. ${ }^{61}$ Sin embargo, este autor considera que, paradójicamente, estas constricciones discursivas también pueden alimentar la audacia judicial en la medida en que acaban citando sus propios precedentes como fundamento de interpretaciones muy libres en el origen. Es más, estas osadías se facilitan en la medida en que las constricciones discursivas también funcionan con los otros actores, especialmente con los Estados, a los que les cuesta mucho cuestionar una decisión judicial en la medida en que puede valorarse como una falta de aceptación de las consecuencias racionales de los principios con los que previamente se habían comprometido. ${ }^{62}$

En el caso de la Corte IDH, estas constricciones discursivas en sentido estricto se han expresado en algunas ocasiones. ${ }^{63}$ Sin embargo, en la medida en que su conciencia de actor fundamental en la salvaguardia de los derechos humanos en la región es tan relevante, esta constricción discursiva decae a favor de un papel proactivo bajo la concepción clara del principio de primacía del derecho internacional y de un derecho internacional global de los derechos humanos:

Otra consideración relevante es el hecho de que el derecho de los derechos humanos forma un sistema integral, universal, que permite e impulsa a los intérpretes a alcanzar el crisol donde los ordenamientos y la jurisprudencia nacional e internacional ponen en común y enriquecen los derechos humanos, con el propósito de mejorar la coherencia y el alcance de las normas que tiene que aplicar (Medina, 2013: 652, 658). ${ }^{64}$

Es el mismo ordre public más arriba referido y que supone un paso más allá del

61. El mismo margen de apreciación nacional al que acabamos de referirnos supone una constricción discursiva en la medida en que uno de los objetivos fundamentales al invocar dicho concepto es preservar el principio de subsidiariedad.

62. Otras formas de plantear lo mismo las encontramos, por ejemplo, en Dworkin (1992: 153) o en Von Bogdandy y Venzke (2012: 15): «Applications of the law in the present have to connect to the past in a way that is convincing in the future».

63. Para ejemplos de disciplina interna y self restraint de la Corte IDH, véase Candia-Falcón (2015: 247248).

64. Una concepción similar se maneja en la propuesta del ius constitutionale commune de América Latina al promover la inserción de los ordenamientos jurídicos estatales en contextos más amplios, subrayando la función doméstica del derecho internacional y todo ello con una idea que orienta a la transformación hacia el respeto a los derechos humanos, la democracia y el Estado de derecho, lejos de defender un derecho específicamente distinto en América Latina (Von Bogdandy, 2015: 13, 16). 
consensualismo propio del derecho internacional. ${ }^{65}$ De nuevo, son claras las palabras de Antônio A. Cançado Trindade:

El derecho de los tratados merece una ilustración pertinente, revelando que ya no está más a merced de la «voluntad» de los Estados y que ella, también, reconoce ciertos valores comunes superiores que la comunidad internacional como un todo considera deben ser preservados. ${ }^{66}$

Esta concepción más la convicción de la necesidad de que este derecho y estos tribunales existen para que los Estados respeten sus obligaciones en materia de derechos humanos, al menos en el contexto del SIDH, confirma la liberación de los jueces respecto de cualquier constricción discursiva y la defensa explícita de ese papel:

En el campo del derecho internacional de los derechos humanos, tendría poco sentido establecer comités, comisiones y tribunales sin poder para desarrollar y dar cuerpo a los principios y normas generales, porque es esta capacidad la que permite hacer que los Estados cumplan con sus obligaciones internacionales de derechos humanos (Medina, 2013: 668).

Lo cual nos devuelve de nuevo al contexto de cada tribunal:

En un gran número de las sentencias de la Corte Interamericana, por el contrario [se está comparando con el TEDH], se trata mayoritariamente de casos en que no solo individuos particulares, sino la sociedad misma se ve o se ha visto afectada por la violación sistemática de derechos humanos [...] El judicial restraint al momento de juzgar violaciones prolongadas y sistemáticas de derechos humanos de grandes sectores de la población podría ser visto como tibieza y falta de compromiso con el juzgamiento histórico de los crímenes de Estado (Ambos y Böhm, 2013: 1.083, 1.085).

\section{El papel de los otros actores relevantes}

Otro conjunto de factores que pueden afectar al grado de activismo de un tribunal internacional es el posicionamiento que adoptan respecto de ellos otros actores relevantes del sistema, puesto que los jueces no operan en el vacío. En primer lugar, es fundamental el papel de los propios Estados, que siguen siendo los sujetos por excelencia del derecho internacional, aunque también la doctrina y los grupos sociales pueden jugar un papel relevante. Hay que tener en cuenta que la autoridad real y efectiva de la jurisprudencia de la Corte depende en parte de la legitimidad alcanzada y de la existencia de otros actores interesados en que se respeten y se sigan sus decisiones (Abramovich, 2009: 23).

65. Dworkin (2014: 282) defiende la necesidad de superar el consensualismo como fundamento del derecho internacional atendiendo al deber de los Estados de «mitigar las falencias del sistema mundial de naciones».

66. Sentencia del caso Caesar con Trinidad y Tobago, párrafo 3. 


\section{Los Estados y el control político}

Otro de los factores que resulta relevante respeto de la mayor o menor autonomía de cualquier órgano jurisdiccional es el tipo y el grado de control político que puede ejercerse sobre él. En el caso del derecho internacional, los Estados pueden abandonar el sometimiento al control judicial, amenazar con incumplir las sentencias, o intentar el control de estos órganos jurisdiccionales a través del nombramiento de sus miembros. Sin embargo, por diversas razones estos mecanismos no son muy viables ni, por tanto, eficaces (Zarbiyev, 2012: 9).

Los tribunales internacionales - con perspectivas temporales mucho más a largo plazo que los Estados- no se dejan amedrentar por las salidas puntuales de Estados. Un Estado solo no puede cambiar el derecho internacional, necesita el apoyo colectivo de otros Estados. Y el incumplimiento de sentencias tiene unos costes, como mínimo en términos de reputación, que los Estados tienen muy en cuenta. Ello no significa que los Estados carezcan de poder. Una sentencia que genere una insatisfacción general sí podría suponer una movilización eficaz por parte de los Estados y es lógico que en alguna medida los jueces sean influidos por la posibilidad de que sus decisiones sean anuladas o incumplidas. Para que sus sentencias sean mínimamente aceptadas, y por tanto cumplidas, han de tener en cuenta la reacción de los Estados (Zarbiyev, 2012: 17).

Lo cierto es que el papel de los Estados es ambivalente ante el desarrollo de la actividad judicial en el derecho internacional. Por un lado, se muestran reacios a la posibilidad de reconocer formalmente el poder de creación de derecho por parte de los jueces, como ya vimos (Boyle y Chinkin, 2007: 267; Vogelfanger, 2015: 258). Por otro lado, tampoco se muestran pródigos en ejercer su función de intérpretes auténticos de los tratados. En puridad, el control político cabría a partir del ejercicio por parte del Estado de su función como primer intérprete de sus propios actos y, entre ellos, los instrumentos creadores de las instancias internacionales de jurisdicción y los tratados que éstos aplican. Sin embargo, su virtualidad práctica se ve reducida por el poco uso que los Estados hacen de ese derecho. Esto, junto a la proliferación de órganos jurisdiccionales y la obligatoriedad de algunos para los Estados miembros de las organizaciones internacionales a las que esos tribunales están ligados, refleja una pérdida de soberanía estatal que no ayuda a compensar la labor jurisdiccional.

En el caso de la Corte IDH, cuando Vogelfanger $(2015: 260,278)$ se pregunta: « $i$ Pueden los tribunales crear derecho internacional?», no duda en responder que "formalmente, desde la teoría clásica de fuentes del derecho, la respuesta sería no. Pero materialmente, la respuesta es sí, al menos la Corte IDH de hecho lo hace y los Estados lo receptan», aunque sea difícil imaginar que los Estados le reconozcan abiertamente la capacidad para crear derecho. Si bien se han producido situaciones de rechazo por parte de ciertos Estados en cumplir las sentencias, se ha amenazado con denunciar la Con- 
vención ${ }^{67}$ e incluso se ha llevado a cabo una denuncia. ${ }^{68}$ Esto es posible porque la Corte, a diferencia del TJUE y el TEDH, es una jurisdicción voluntaria dentro de la OEA. La mayor parte de las sentencias y decisiones de la Corte son acatadas en los términos que comentamos anteriormente. En definitiva, el mayor o menor grado de activismo de la Corte existe precisamente porque los Estados lo permiten. «La Corte Interamericana se caracteriza por su activismo judicial, lo cual podría llamarse "audacia" si tal activismo se enfrentase a resistencias por parte de los Estados — quienes, por el contrario, celebran su forma de actuar-» (Ambos y Böhm, 2013: 1.085).

Esto es importante porque la mayor parte de las críticas inciden en que la falta de legitimidad vendría porque la Corte no habría sido habilitada por los Estados para adoptar determinadas decisiones. En la medida en que los Estados aceptan ese comportamiento judicial, al menos por omisión, están legitimando su labor. «Si una mayoría significativa está de acuerdo con la manera en la cual la Corte ejerce sus poderes, no hay razón para preguntarse si se trata de law-making o policy-making. Si la aceptación de los Estados se reduce, la situación debería ser revisada» (Medina, 2013: 668).

Es más, las últimas modificaciones de los reglamentos de la Comisión y la Corte $\mathrm{IDH}$, a los que ya hemos hecho referencia, lejos de limitar sus funciones, han consolidado su labor al reducir el margen de la Comisión para la remisión de los casos, al permitir al particular presentar alegaciones autónomas en el proceso ante la Corte y por la figura del defensor interamericano de oficio que representa a las presuntas víctimas que no tengan representación legal acreditada.

Por último, Pascual Vives (2013: 258-262) muestra la importancia de la voluntad de los Estados en la jurisprudencia de los tribunales regionales de derechos humanos al tratar el margen de apreciación nacional desde una aproximación consensualista. Este autor sitúa el consenso como elemento clave para que un tribunal se decante por hacer uso o no del margen de apreciación nacional, dentro del consensualismo propio del derecho internacional. De forma que es el consenso de los Estados parte de estos tribunales lo que les permite ampliar el alcance de las obligaciones estatales en esta materia o abrir el catálogo de derechos fundamentales. Parece ser que incluso podría apreciarse cierta relación entre las resoluciones adoptadas por la Asamblea General de la OEA y algunos desarrollos de la jurisprudencia de la Corte IDH en ciertos sectores muy concretos, como el reconocimiento del principio de no discriminación debido a orientación sexual. De este modo, a partir de varias resoluciones sobre derechos humanos, orientación sexual e identidad de género aprobadas por consenso por la Asamblea

67. «Entre esos países se halla Perú, el que en enero de 2007 expresó a la Corte su decisión de no cumplir la sentencia en el caso del Penal de Miguel Castro Castro, ofreciendo otro tipo de reparaciones en compensación (por ejemplo, prestaciones en materia de salud, educación, etcétera). Perú, ante la situación, incluso ha señalado su intención de retirarse del Pacto de San José. Similares situaciones se han dado con Trinidad y Tobago, Guatemala, Honduras, El Salvador, Venezuela, entre otros» (Drnas de Clément, 2010: 2201).

68. Venezuela presentó el 10 de septiembre de 2012 un instrumento de denuncia de la CADH según el artículo 78.1 de dicha Convención. La denuncia surtió efecto a partir del 10 de septiembre de 2013 (Corte IDH, 2018: 15). 
General, la Corte realizó una interpretación evolutiva del derecho a la vida familiar. Otro ejemplo de esta correlación lo encontramos en el reconocimiento del derecho al acceso a la identidad biológica de los progenitores y lo aprobado en sentido similar tanto por la Asamblea General de la OEA como por el Comité Jurídico Interamericano respecto al derecho a la identidad. ${ }^{6}$

\section{La función legitimadora de la doctrina}

Zarbiyev (2012: 10 y 21) ${ }^{70}$ sostiene que una razón fundamental para legitimar la labor creativa de los tribunales internacionales radica en el papel jugado por la doctrina a través de su discurso teórico sobre el derecho internacional, en el que han situado a los jueces en la posición de colmar las lagunas, clarificar las ambigüedades y, en definitiva, poner remedio a todas las deficiencias de la función legislativa del derecho internacional, identificando de manera sistemática las normas de derecho internacional con la interpretación judicial de las mismas. De hecho, esta labor doctrinal es fundamental para que la creatividad judicial pase desapercibida y se legitime como una cuestión de principio en la medida en que no se identifica ninguna arbitrariedad.

En el caso de la Corte IDH, sin embargo, parte de la doctrina ha desarrollado críticas enérgicas, muchas de las cuales ya hemos comentado. La base de las críticas principales que recibe la Corte IDH se encuentra en una concepción particular del derecho internacional, de su relación con los derechos internos y del SIDH, que no se dan entre la doctrina más representativa de los ámbitos de otros sistemas equivalentes de protección internacional de los derechos humanos como el del Consejo de Europa y su tribunal de derechos humanos.

Algunos autores se han centrado en los problemas que algunas obligaciones impuestas por la Corte respecto de la investigación y sanción de delitos tendrían respecto a las garantías de los imputados en lo que se ha denominado el punitivismo de la jurisprudencia de la Corte. ${ }^{71}$ También se le ha criticado el activismo judicial en sí mismo por alejarse del mandato explícito de la CADH (ampliación del contenido de los derechos

69. Sentencia de fondo y reparaciones del caso Gelman con Uruguay, párrafo 123; y Resolución AG/RES. 2286 (XXXVII-O/o7), «Programa interamericano para el registro civil universal y "derecho a la identidad"», Organización de los Estados Americanos, 5 de junio de 2007, disponible en https://bit.ly/2uNSTAY; Resolución AG/RES. 2362 (XXXVIII-O/o8), Organización de los Estados Americanos, 3 de junio de 2008, disponible en https://bit.ly/2LNBiiV; Comité Jurídico Interamericano, resolución CJI/doc. 276/o7 rev. 1, "Opinión "sobre el alcance del derecho a la identidad"», 10 de agosto de 2007, párrafos 11.2 y 18.3.3, disponible en https://bit.ly/2AcSnlh, ratificada por resolución CJI/RES.137 (LXXI-O/o7), «El alcance del derecho a la identidad», Comité Jurídico Interamericano, 10 de agosto de 2010, disponible en https://bit.ly/2LEo63b.

70. Zarbiyev (2012: 25) cita un comentario precioso de Mohammed Bedjaoui, que fue presidente del Tribunal Internacional de Justicia, que muestra claramente lo público y notorio de esta relación entre la doctrina y la jurisprudencia internacional.

71. En sentido contrario: «No se trata de procesos penales, sino de procesos propios del derecho internacional, que tiene precisamente por fin la limitación del poder estatal en favor del respeto de los derechos individuales» (Ambos y Böhm, 2013: 1.086). 
o creación de nuevos derechos; creación, modificación, supresión de norma pactada), y por usurpar competencias democráticamente atribuidas a los poderes del Estado o al Estado mismo como sujeto soberano, al ordenar modificaciones constitucionales o legislativas, firmar tratados, medidas de políticas públicas e intromisiones en el poder judicial. Es significativo que Ezequiel Malarino, quien posiblemente hace la crítica más amplia y sistemática en ese sentido, afirme que «el sistema interamericano, a diferencia de otros sistemas jurídicos, no abre sus sistemas de las fuentes a todo el derecho internacional» (Malarino, 2010: 29).

Hay críticas que suponen directa y profundamente el cuestionamiento de la autoridad de la Corte IDH y cuestionan la legitimidad del derecho internacional desde la perspectiva de la deliberación democrática:

El problema más importante [...] tiene que ver con los déficits de legitimidad que suelen afectar a todas las autoridades invocadas como fuentes del derecho internacional. [...] Como suele ocurrir con los tribunales internacionales, los miembros de la Corte no son elegibles popularmente y tampoco son removibles por los ciudadanos. [...] Dificultades existen para - sin más - dotar de autoridad al derecho internacional (Gargarella, 2016: 425-427).

Son perspectivas en las que el derecho internacional aparece opuesto al derecho nacional, como derecho "extranjero», ${ }^{72}$ sin considerar a las comunidades nacionales como parte de la comunidad internacional que está en los fundamentos del desarrollo del derecho internacional contemporáneo en el que la Corte se inserta y desde el que defiende y practica la idea de un derecho internacional global de los derechos humanos.

Como explica Héctor Fix-Zamudio, en una época reciente

se observa la tendencia de algunas constituciones latinoamericanas a superar la desconfianza tradicional hacia los instrumentos internacionales y, en general, hacia el derecho internacional, para introducir, de manera paulatina una cierta preeminencia, así sea cautelosa, de las normas de carácter supranacional (Fix-Zamudio, 1993: 56).

Esa desconfianza parece haberse concretado en un concepto de soberanía estatal que funciona como un "escudo» protector de injerencias internas, comprensible en la expresión de un importante escepticismo frente a los organismos económicos internacionales, pero no respecto de las instituciones internacionales que abogan por la salvaguarda de los derechos humanos, la democracia y el Estado de derecho. Aquí, la soberanía en lugar de ser una figura de cierre se convierte «en un principio funcional que se pone al servicio de los principios fundamentales. Las instituciones del derecho

72. En sentido contrario: «El derecho internacional, particularmente en este caso, el derecho interamericano $[\ldots]$ no debe entenderse como derecho extranjero» (Sierra Porto, 2016: 47). O también: «La Convención Americana adquiere una eficacia de la más alta importancia práctica por operar como derecho interno de aplicación inmediata por los órganos de los Estados parte y por aplicarse en el marco del derecho internacional» (Odimba-On’Etambalako, 2006: 715). 
internacional se entienden así como conquistas del derecho internacional» (Von Bogdandy, 2015: 25-27).

Abramovich responde a estas críticas centradas en la limitación de la autonomía política de los Estados en materia de derechos humanos debido al modo de operar de la Corte, refiriendo el papel que actores sociales e institucionales de esos Estados juegan tanto en la creación como en la aplicación doméstica de las normas y estándares internacionales de derechos humanos:

La aplicación de normas internacionales en el ámbito nacional no es un acto mecánico, sino un proceso que involucra también diferentes tipos de participación y deliberación democrática e incluso un amplio margen para la relectura o reinterpretación de los principios y normas internacionales en función de cada contexto nacional (Abramovich, 2009: 25).

Von Bogdandy, en su propuesta de ius constitutionale commune de América Latina, defiende el papel tanto de la Corte como de algunos tribunales constitucionales de la región, porque

muchas sentencias que bajo el viejo paradigma parecerían un activismo judicial cuestionable, se entienden bajo el nuevo paradigma [que enfatiza el poder judicial como motor de innovaciones transformadoras] como propios del poder judicial de una democracia constitucional que de manera incremental ayuda a realizar el nuevo proyecto constitucional (Von Bogdandy, 2015: 23).

Estas discusiones doctrinales son importantes no solo por la función legitimadora a la que alude Zarbiyev, sino también porque, precisamente, como explica Víctor Abramovich:

Un factor importante para la consolidación de una mayor apertura de los sistemas de justicia nacionales a la aplicación del derecho internacional es la conformación de una fuerte comunidad académica [...]. No solo es indispensable para asegurar la aplicación de los estándares interamericanos a nivel doméstico, sino también para obligar a rendir cuentas a los propios órganos del SIDH» (Abramovich, 2009: 26).

A lo que añadió, hace menos de una década, que las decisiones de la Corte y de la Comisión eran poco comentadas, muy poco criticadas y en varios países escasamente conocidas.

\section{Consideraciones de legitimidad social}

El papel de otros actores sociales distintos del Estado y la doctrina también puede ser relevante. En determinados contextos, las demandas sociales pueden promover bien el activismo, bien la contención judicial. Los jueces internacionales no son inmunes a las opiniones que sobre ellos pueden desarrollar los grupos sociales a los que pertenecen (Zarbiyev, 2012: 30). Es más, «las sentencias de los tribunales pueden transformar una 
sociedad únicamente si esta transformación está respaldada y es promovida por importantes grupos sociales» (Von Bogdandy, 2015: 23). De hecho, grupos de la sociedad civil ven con frecuencia en estos tribunales una oportunidad para avanzar en sus demandas sociales:

Particularmente en áreas tales como derechos humanos o derecho del medioambiente existe una tendencia a afirmar nuevas normas de derecho consuetudinario a voluntad de cara a avanzar en agendas políticas y sociales — una actividad especialmente perseguida por las ONG (Boyle y Chinkin, 2007: 285).

No cabe duda de que la Corte IDH ha sido vista como una oportunidad para los movimientos civiles en defensa de los derechos humanos en América Latina. Viviana Krsticevic lo explica así:

Las organizaciones no gubernamentales han tenido un papel central en el desarrollo de la protección internacional interamericana, principalmente por su representación de las víctimas de violaciones de los derechos humanos. Ellas han facilitado y promovido el acceso de las víctimas de violaciones de derechos humanos ante la Comisión y la Corte, han promovido el tratamiento de un amplio rango de violaciones de derechos humanos por parte del sistema interamericano y han trabajado para el fortalecimiento de este sistema de modo estructural (Krsticevic, 2001: 408).

No solo las ONG en sentido estricto, sino todos los grupos de la sociedad civil latinoamericana implicados en la defensa de la democracia y los derechos humanos (organizaciones que representan a las víctimas, organizaciones comunitarias, sindicatos, organizaciones de derechos humanos, organizaciones de mujeres, defensores de los derechos de los pueblos indígenas) ven en la Corte un mecanismo más para intentar avanzar en sus objetivos. No solo para denunciar violaciones de derechos humanos, sino también para alcanzar posiciones privilegiadas de diálogo con los Gobiernos. Con frecuencia usan los estándares jurídicos fijados por el SIDH para fiscalizar la acción de sus Estados e, incluso, para impugnarlas ante los tribunales nacionales (Abramovich, 2009: 14).

Al fin y al cabo, los derechos humanos son la piedra angular de la movilización de la sociedad civil, y las sentencias judiciales sobre estos derechos son con frecuencia producto de la lucha de grupos sociales (Von Bogdandy, 2009: 17).

En definitiva, «existe una comunidad de actores sociales, políticos e incluso académicos, que se consideran protagonistas de la evolución del propio SIDH, y participan activamente del proceso de implementación nacional de sus decisiones y principios» (Abramovich, 2009: 24). Es difícil imaginar que la Corte se abstraiga de esta realidad, de este apoyo social y de esta demanda de protección e impulso de los derechos humanos y la democracia. 


\section{Conclusiones}

La Corte IDH ha aprovechado los elementos jurídico-estructurales con los que cuenta como tribunal internacional de derechos humanos para adoptar una labor interpretativa extensiva y pro homini, sin dejar que factores como su carácter no permanente o el no acceso directo de los particulares a su jurisdicción hayan mermado esa labor. Ello se debe en gran medida a los aspectos intrínsecos del tribunal: la fuerza de la propia concepción que los miembros de la Corte IDH tienen de su función en el contexto de Estados con aún graves carencias institucionales como Estados de derecho y democracias, no solo aleja posibles doctrinas prudenciales y constricciones discursivas en su quehacer, sino que les permite hacer valer con determinación su rol garantista de los derechos humanos a través del control de convencionalidad y la generosa interpretación del principio de la subsidiariedad de su jurisdicción respecto de las jurisdicciones nacionales. Todo ello en un escenario en que los Estados no solo no se han atrevido a hacer valer de manera efectiva sus armas frente a la Corte, sino que han aceptado como miembros de la OEA modificaciones que afianzan su labor, si bien la Corte IDH tiene su principal apoyo en los grupos de la sociedad civil que vuelcan en ella sus esperanzas y esfuerzos por hacer realidad el cumplimiento pleno de la CADH.

Las críticas principales recibidas por la Corte (que defienden que ésta decida de manera exclusiva de acuerdo con el texto literal de la $\mathrm{CADH}$ ) chocan frontalmente con la concepción del derecho de los derechos humanos que defienden, en general, sus jueces, caracterizado por la disminución del consensualismo en pro de un orden público superior en esta materia. Es más, el cuestionamiento de la labor de la Corte con frecuencia se traslada a una falta de aceptación general de la primacía del derecho internacional respecto al derecho interno de los Estados.

La calificación como instrumento vivo a los tratados regionales de derechos humanos fue desarrollada por el TEDH sin generar un cuestionamiento de su labor equivalente al que vive la Corte IDH. Si bien es cierto que el Tribunal europeo ha desarrollado una jurisprudencia mucho más autorrestrictiva (principalmente a través del margen nacional de apreciación), es fundamental tener en cuenta la importante diferencia de contexto en el que se encuentran ambos tribunales, principalmente en lo referido a las violaciones masivas de derechos y situaciones estructurales de impunidad.

Si precisamente uno de los desafíos del derecho internacional es evitar la fragmentación sustantiva que podría acarrear la proliferación de órganos jurisdiccionales, parece lógico y coherente, y bueno para los Estados, las instituciones internacionales y, sobre todo, las personas, que haya una coordinación e incluso un entendimiento entre todos los órganos encargados de la salvaguardia de los derechos humanos, internacionales y también nacionales. De este modo, al tiempo que se pueden respetar las posibles singularidades regionales (es paradigmática en este sentido la jurisprudencia de la Corte IDH respecto de los pueblos indígenas), se posibilita un derecho global de los derechos humanos ante la comprensión de una dignidad humana universal. 


\section{Agradecimientos}

Este trabajo se ha desarrollado en el marco del proyecto de investigación «Jueces en democracia: La filosofía política de la Corte Interamericana de Derechos Humanos», proyecto financiado por el Ministerio de Economía, Industria y Competitividad de España. Referencia: DER2016-79805-P (AEI/FEDER, UE).

\section{Referencias}

Abalde Cantero, Óscar (2016). Naturaleza jurídica de las decisiones de la Corte Internacional de Justicia: Fuerza obligatoria y fuerza ejecutiva. Pamplona: Thomson Reuters Aranzadi.

AвRAmovich, Víctor (2009). «De las violaciones masivas a los patrones estructurales: Nuevos enfoques y clásicas tensiones en el sistema interamericano de derechos humanos». Sur: Revista Internacional de Derechos Humanos, 11 (6): 7-39. Disponible en http://bit.ly/2EEVOma.

Амвоs, Kai y María Laura Böhm (2013). «Tribunal Europeo de Derechos Humanos y Corte Interamericana de Derechos Humanos: ¿Tribunal tímido vs. tribunal audaz?». En Eduardo Ferrer Mac-Gregor y Alfonso Herrera García (coordinadores), Diálogo jurisprudencial en derechos humanos entre tribunales constitucionales y cortes internacionales (pp. 1.057-1.088). Ciudad de México: Tirant Lo Blanch. Disponible en https://bit.ly/2GxooWO.

Barbosa Delgado, Francisco (2013). «El margen nacional de apreciación en el derecho internacional de los derechos humanos: Entre el Estado de derecho y la sociedad democrática». En Eduardo Ferrer Mac-Gregor y Alfonso Herrera García (coordinadores), Diálogo jurisprudencial en derechos humanos entre tribunales constitucionales y cortes internacionales (pp. 1.089-1.118). Ciudad de México: Tirant Lo Blanch. Disponible en https://bit.ly/2GxooWO.

Bellei Tagle, Carlos (2016). "Consecuencias jurisdiccionales asociadas a la multiplicación de tribunales internacionales: ¿En qué consisten los potenciales riesgos?». Anuario Colombiano de Derecho Internacional, 9: 17-49. DOI: 10.12804/ acdi9.1.2016.01.

Boyle, Alan y Christine Chinkin (2007). The making of international law. Oxford: Oxford University Press.

Candia-Falcón, Gonzalo (2015). «El Estado de derecho y la Corte Interamericana de Derechos Humanos». Dikaion, Revista de Fundamentación Jurídica de la Universidad de La Sabana, 24 (2): 225-252. DOI: 10.5294/dika.2015.24.2.2.

Cappelletti, Mauro (2015). «Is the European Court of Justice "running wild”?». European Law Review, 3: 311-322.

CorTe IDH, Corte Interamericana de Derechos Humanos (2015). «Cuadernillo de jurisprudencia de la Corte Interamericana de Derechos Humanos 7: Control de convencionalidad». San José: Corte IDH-Ministerio de Relaciones Exteriores de Dinamarca. Disponible en https://bit.ly/2wtERCW. 
-. (2017). Informe anual 2016. San José.

-. (2018). Informe anual 2017. San José.

-. (2018). Jurisprudencia. Disponible en: https://bit.ly/1LoCNsg

Drnas DE Clément, Zlata (2010). «Claroscuros del aporte de la Corte Interamericana de Derechos Humanos al desarrollo del derecho internacional de los derechos humanos». En Eduardo Rey Tristán y Patricia Calvo González (editores), XIV Encuentro de latinoamericanistas españoles (pp. 2.190-2.202). Disponible en http://bit. ly/2Ex9oHu.

DwOrkin, Ronald (1992). Los derechos en serio. Barcelona: Planeta-Agostini.

-. (2014). «Una nueva filosofía para el derecho internacional». Lecciones y Ensayos, 93: 275-284.

Ferrer MaC-Gregor, Eduardo (2016). «El derecho a la verdad en el derecho internacional de los derechos humanos (y eventual desarrollo como derecho autónomo en la jurisprudencia interamericana)». En Pablo Santolaya Machetti e Isabel Wences (coordinadores). La América de los derechos. Madrid: Centro de Estudios Políticos y Constitucionales.

Fix-Zamudio, Héctor (1993). «La evolución del derecho internacional de los derechos humanos en las constituciones latinoamericanas». En Instituto Interamericano de Derechos Humanos (pp. 51-66). Serie Estudios de Derechos Humanos. Tomo 2. Disponible en https://bit.ly/2GwBqoU.

García RocA, Javier (2007). «La muy discrecional doctrina del margen de apreciación nacional según el Tribunal Europeo de Derechos Humanos: Soberanía e integración». Teoría y Realidad Constitucional, 20: 117-143. DOI: 10.5944/trc.20.2007.6778.

GARgARELla, Ramón (2016). «Justicia penal internacional y deliberación democrática». En Pablo Santolaya Machetti e Isabel Wences (coordinadores), La América de los derechos. Madrid: Centro de Estudios Políticos y Constitucionales.

GonzÁlez Le SAux, Marianne y Claudio Nash Rojas (editores) (2011). Transparencia, luch a contra la corrupción y el sistema interamericano de derechos humanos: Informe de la tercera reunión regional de especialistas (pp. 10-51). Santiago: Centro de Derechos Humanos, Facultad de Derecho Universidad de Chile. Disponible en https:// bit.ly/2POSt4T.

Hart, Herbert (1961). El concepto de derecho. Buenos Aires: Abeledo Perrot.

KMIEC, Keenan (2004). "The origin and current meanings of "judicial activism"». California Law Review, 92 (5): 1.441-1.477. DOI: 10.15779/Z38X71D.

KrsticeVic, Viviana (2001). «El papel de las ONG en el sistema interamericano de protección de los derechos humanos: Trámite de los casos ante la Corte Interamericana de Derechos Humanos». En Memoria del Seminario Interamericano de Protección de los Derechos Humanos en el Umbral del Siglo XXI. Tomo 1. San José. Disponible en https://bit.ly/2EFNUsT.

LAUTERPACHT, Hersch (1982). The development of international law by the International Court. Cambridge: Cambridge University Press.

LozAdA, Alí (2018). "Activismo judicial y derechos sociales: Un enfoque postpo- 
sitivista». DOXA: Cuadernos de Filosofía del Derecho, 41: 211-226. DOI: 10.14198/ DOXA2018.41.11.

Malarino, Ezequiel (2010). «Activismo judicial, punitivización y nacionalización: Tendencias antidemocráticas y antiliberales de la Corte Interamericana de Derechos Humanos». En Instituto de Estudios Jurídicos de la UNAM (pp. 25-61). Disponible en https://bit.ly/2SZExr4.

MARTINón Quintero, Ruth (2016). «Corrupción y derechos humanos: En particular, la Corte Interamericana de Derechos Humanos». Eunomía: Revista en Cultura de la Legalidad, 10: 8-33. Disponible en http://bit.ly/2EDETjW.

Medina, Cecilia (2013). "The role of international tribunals: Law-making or creative interpretation?». En Dinah Shelton (editor), The Oxford handbook of international human rights law. Cambridge: Cambridge University Press. Disponible en https:// bit.ly/2EDLk6z.

Nieto, Alejandro (2007). Crítica de la razón jurídica. Madrid: Trotta.

NúÑEz MARín, Raúl Fernando (2014). «Ronald Dworkin y el activismo internacional». Análisis Internacional, 5 (2): 203-218. Disponible en http://bit.ly/2EEjjvr.

Odimba-On'Etambalako, Jean Cadet (2006). «Logros alcanzados y ajustes pendientes en la Corte Interamericana de Derechos Humanos». Anuario Mexicano de Derecho Internacional, 6: 703-727. DOI: 10.22201/iij.24487872e.2006.6.167.

Pascual Vives, Francisco José (2013). «El margen de apreciación nacional en los tribunales regionales de derechos humanos: Una aproximación consensualista». Anuario Español de Derecho Internacional, 29: 217-262. Disponible en http://bit.ly/2EDIn5M.

Quispe Remón, Florabel (2016). «La protección de los derechos humanos en el sistema interamericano: su evolución y una visión actual». Anuario Español de Derecho Internacional, 32: 225-258. DOI: 10.15581/010.32.225-258.

Rasmussen, Hjalte (1986). On law and policy in the European Court of Justice. Dorbrecht: Martinus Nijhoff.

Rodríguez Rescia, Víctor Manuel (1997). La ejecución de sentencias de la Corte Interamericana de Derechos Humanos. San José: Investigaciones Jurídicas.

SÁnchez-Molina, Pablo (2016). «Margen de apreciación nacional (en los sistemas de protección internacional de los derechos humanos)». Eunomía: Revista en Cultura de la Legalidad, 9: 224-231. Disponible en http://bit.ly/2EDETjW.

Sierra Porto, Humberto (2016). «Treinta y cinco años de funcionamiento de la Corte Interamericana de Derechos Humanos». En Pablo Santolaya Machetti e Isabel Wences (coordinadores), La América de los derechos. Madrid: Centro de Estudios Políticos y Constitucionales.

Ventura Robles, Manuel (2002). «La Corte Interamericana de Derechos Humanos: Camino hacia un tribunal permanente». Revista IIDH, 32-33: 271-310. Disponible en https://bit.ly/2UXx9y4.

VIANA GARCÉs, Andrée (2008). «Sistema europeo y americano de protección de derechos humanos: Coincidencias, fraccionamientos temporales y mutuas influencias». En Miguel Revenga Sánchez y Andrée Viana Garcés (editores), Tendencias jurispru- 
denciales de la Corte Interamericana y el Tribunal Europeo de Derechos Humanos. Valencia: Tirant Lo Blanch.

Villanueva Flores, Rocío (2018). «Activismo judicial y límites del derecho en la actuación de la Corte Interamericana de Derechos Humanos». DOXA: Cuadernos de Filosofía del Derecho, 41: 151-169. DOI: 10.14198/DOXA2018.41.08.

Vogelfanger, Alan Diego (2015). «La creación de derecho por parte de los tribunales internacionales: El caso específico de la Corte Interamericana de Derechos Humanos». Pensar en Abierto, 7 (4): 251-284. Disponible en https://bit.ly/2UXXpYY.

Von Bogdandy, Armin (2015). «Ius constitutionales commune en América Latina: Una mirada a un constitucionalismo transformador». Derecho del Estado, 34: 3-50. DOI: 10.18601/01229893.n34.01.

Von Bogdandy, Armin e Ingo Venzke (2012). «In whose name? An investigation of International Court's public authority and its democratic justification». The European Journal of International Law, 23 (1): 7-41. Disponible en http://bit.ly/2EE5wpo.

Zarbiyev, Fuad (2012). "Judicial activism in international law: A conceptual framework for analysis». Journal of International Dispute Settlement, 3 (2): 1-32. DOI: 10.1093/jnlids/idsoo5.

\section{Sobre la autora}

Ruth Martinón Quintero es doctora por la Universidad Carlos III de Madrid, España. Licenciada en Derecho por la Universidad Nacional de Educación a Distancia, España, y licenciada en Ciencia Política y de la Administración por la Universidad Complutense de Madrid, España. Es profesora de Derecho Internacional Público y Relaciones Internacionales en la Universidad de La Laguna, España, en la cual es también directora académica del Centro de Documentación Europea y Miembro del Centro de Estudios de Desigualdad y Gobernanza. Su correo electrónico es ruth.martinon@ull.es. 
La Revista de Derecho Público es publicada, desde 1963, dos veces al año por el Departamento de Derecho Público de la Facultad de Derecho de la Universidad de Chile. Su propósito es la difusión de los avances del derecho público nacional e internacional y la socialización de artículos de investigación inéditos tanto de la comunidad académicas nacional e internacional.

DIRECTORA

Ana María García Barzelatto

SECRETARIO DE REDACCIÓN

Felipe Peroti Díaz

(fperoti@derecho.uchile.cl)

SITIO WEB

revistaderechopublico.uchile.cl

CORREO ELECTRÓNICO

publico@derecho.uchile.cl

LICENCIA DE ESTE ARTÍCULO

Creative Commons Atribución Compartir Igual 4.0 Internacional

La edición de textos, el diseño editorial

y la conversión a formatos electrónicos de este artículo

estuvieron a cargo de Tipográfica

(www.tipografica.cl). 